pathy. Only one abnormal ratio was found in the 75 diabetics of grades 0 and 1 , in whom autonomic function was normal on conventional testing. In grade 2,41 of the 47 diabetics gave abnormal or borderline results. The ratios in the 12 with symptomatic autonomic neuropathy (grade 3 ) were all well below the normal range.

Repeat measurements of the E:I ratio varied little; the coefficients of variation were $8.9 \%$ in healthy subjects and $5.3 \%$ in diabetics.

\section{Discussion}

Measurement of variation in heart rate during deep breathing is generally agreed to be a sensitive index of autonomic dysfunction, comparing favourably with tests based on changes in posture. ${ }^{13}$ Adaptation of a repeated deep breathing test for use with a conventional electrocardiogram to obtain an $\mathrm{E}: \mathrm{I}$ ratio was first described by Sundkvist et al, ${ }^{11}$ which represented a considerable simplification in technique over previous methods. These authors did not define the influence of age on this ratio but set the lower limit of normal at an E:I ratio of $1 \cdot 1$. When applied to the ratios measured here this limit gave three falsepositive and 16 false-negative diagnoses. The age-related normal range described in this report increases the diagnostic value of the $E$ :I ratio test since there were only one false-positive and six false-negative results.

There does not appear to be any advantage in averaging the variations in heart rate from a sequence of forced respirations compared with measuring the change resulting from a single deep breath. The change in rate is greater on the first breath ${ }^{12}$ and, in contrast to the mean, is not affected by the resting heart rate, ${ }^{5}$ which simplifies the construction of a normal range.

I conclude, therefore, that the E:I ratio test of sinus arrhythmia is an accurate and reliable method of screening diabetic patients for autonomic dysfunction. It may be performed rapidly by a nurse or technician with any electrocardio- graphic apparatus and immediate reference made to the normal range. It is thus appropriate for use in the diabetic clinic.

I am grateful to the British Diabetic Association for financial support, Professor S E Smith for statistical advice, and Professor P H Sönksen and Dr C Lowy for allowing me to study their patients.

\section{References}

1 Mackay JD, Page MMcB, Cambridge J, Watkins PJ. Diabetic autonomic neuropathy. The diagnostic value of heart rate monitoring. Diabetologia $1980 ; 18: 471-8$.

${ }^{2}$ Ewing DJ, Borsey DQ, Bellavere F, Clarke BF. Cardiac autonomic neuropathy in diabetes: comparison of measures of $R-R$ interval variation. Diabetologia $1981 ; 21: 18-24$.

3 Anonymous. Diagnosis of autonomic neuropathy. (Editorial.) $\mathrm{Br} \mathrm{Med} \mathrm{J}$ 1978;ii:910-1.

4 Wheeler T, Watkins PJ. Cardiac denervation in diabetes. $\mathrm{Br}$ Med $\mathcal{F}$ 1973; iv :584-6.

5 Smith SE, Smith SA. Heart rate variability in healthy subjects measured with a bedside computer-based technique. Clin Sci 1981;61:379-83.

6 Wieling W, van Brederode JFM, de Rijk LG, Borst C, Dunning AJ. Reflex control of heart rate in normal subjects in relation to age: a data base for cardiac vagal neuropathy. Diabetologia 1982;22:163-6.

7 Smith SE, Smith SA, Brown PM, Fox C, Sönksen P. Pupillary signs in diabetic autonomic neuropathy. $\mathrm{Br}$ Med F 1978;ii:924-7.

${ }^{8}$ Smith SA, Smith SE. Evidence for a neuropathic aetiology in the small pupil of diabetes mellitus. Br $\mathcal{F}$ Ophthalmol (in press).

9 Baker RT, Nelder JA. The GLIM system manual for release 3 . Oxford: Numerical Algorithms Group, 1978.

10 Fisher RA. Intraclass correlations. In: Statistical methods for research workers. 14th ed. Edinburgh: Oliver and Boyd, 1970:217-49.

11 Sundkvist G, Almer L-O, Lilja B. Respiratory influence on heart rate in diabetes mellitus. $\mathrm{Br}$ Med $\mathcal{F} 1979 ; \mathrm{i}: 924-5$.

12 Bennett T, Farquhar IK, Hosking DJ, Hampton JR. Assessment of methods for estimating autonomic nervous control of the heart in patients with diabetes mellitus. Diabetes 1978;27:1167-74.

(Accepted 16 September 1982)

\title{
Microscopic colitis-a cause of chronic watery diarrhoea
}

\author{
JEREMY G C KINGHAM，DAVID A LEVISON，JOANNA A BALL，ANTHONY M DAWSON
}

\begin{abstract}
Six patients with severe watery diarrhoea were found to have microscopic total colitis. None had any abnormality detectable by conventional tests used to diagnose inflammatory bowel disease-namely, barium radiology and endoscopy. The diagnosis could only be made by microscopic examination of biopsy specimens from the apparently normal colon. Anaemia, raised erythrocyte sedimentation rate, hypokalaemia, and hypoalbuminaemia were common findings. Smallbowel function was normal in all, though three patients had jejunal lesions of uncertain relevance but seemingly unrelated to the diarrhoea. The five patients given anti-inflammatory drugs showed a satisfactory response
\end{abstract}

\footnotetext{
Departments of Gastroenterology and Pathology, St Bartholomew's Hospital, London EC1A 7BE

JEREMY G C KINGHAM, MD, MRCP, senior medical registrar

DAVID A LEVISON, MB, MRCPATH, senior lecturer

JOANNA A BALL, MB, BS, house physician

ANTHONY M DAWSON, MD, FRCP, consultant physician
}

with improvement of the diarrhoea and colonic inflammation and return to normal of the abnormal laboratory findings.

Microscopic colitis is responsible for a proportion of cases of intractable diarrhoea of obscure origin and rectal and colonic biopsies should be undertaken in such cases.

\section{Introduction}

Occasionally patients with large-volume diarrhoea undergo extensive investigations with no cause found. We describe six such patients seen over the past 10 years in whom biopsy of an apparently normal colon showed microscopic colitis and led to satisfactory treatment.

\section{Patients and methods}

All patients were referred for inpatient investigation of diarrhoea after negative findings on investigations at other hospitals. All were white and none had lived abroad. Further investigations excluded (as far as this is possible) diarrhoea induced by tumour or laxatives. No 
patients had any abnormality on the findings of conventional tests currently used to diagnose inflammatory bowel disease-namely, sigmoidoscopy, colonoscopy, barium enema, and small-bowel meal. The tables give details of the patients.

\section{CLINICAL FEATURES}

In all patients diarrhoea was the main complaint, with maximum daily stool volumes from 900 to $2100 \mathrm{ml}$. Not every patient had diarrhoea on every day during time in hospital, some passing normal volumes of semiformed stool on occasions, but the mean documented daily stool volume exceeded $500 \mathrm{ml}$ in all cases (normal $50-250 \mathrm{ml}$ ).

Table I shows the main clinical features. Four of the six patients were women. Age ranged from 39 to 62 years and diarrhoea had been present for from three months to 25 years at the time of diagnosis. The stools were loose or watery and pale to dark brown but without blood. The average daily frequency of bowel movement was six. All patients had urgency of defecation and nocturnal diarrhoea; four were occasionally incontinent. All had some associated abdominal discomfort and malaise, though none suffered severe pain. Weight loss of more than $7 \mathrm{lb}(3.2 \mathrm{~kg})$ was noted in five, and ankle oedema in two. One patient was known to have coeliac disease, though was in remission on gluten-free diet. All patients had previously tried symptomatic remedies for their diarrhoea without noticeable benefit. The father of one patient had colitis, while her two siblings had juvenile rheumatoid arthritis.

No specific features were noted on physical examination though weight loss was obvious in two. No perianal disease other than excoriation secondary to diarrhoea was seen.

\section{FINDINGS ON ENDOSCOPY AND RADIOLOGY}

Sigmoidoscopy was performed on several occasions in all patients and total colonoscopy at least once. These examinations gave unequivocally normal results. High-quality double-contrast barium enema was performed on all patients and more than once in five of the six. None showed any of the changes of inflammatory bowel disease but one showed sigmoid diverticulosis and in one the colon was rather dilated (diameter $5 \mathrm{~cm}$ ) though the haustral pattern and mucosal outline were normal. Barium meal and small-bowel meal examinations were performed separately at least once in all patients. No mucosal abnormalities were seen, though in three the transit time from mouth to caecum was rather prolonged (greater than six hours) and in two of these the jejunum was considered slightly dilated. Of these two, one (case 2) had subtotal villous atrophy. There was no suggestion of inflammatory bowel disease in any of the barium studies of the upper intestinal tract.

\section{HISTOLOGICAL FINDINGS}

Rectum and colon-Microscopic colitis was diagnosed histologically as the colon was macroscopically normal. All the rectal and colonic biopsy specimens ( 31 in all) from these six patients were abnormal with diffuse, mild but definite chronic inflammation of the lamina propria (fig 1). The inflammation was composed predominantly of plasma cells with various admixtures of lymphocytes, macrophages, eosinophil and neutrophil polymorphs. No granulomata were seen. There was only minor distortion of the glands, and goblet cells were, at most, only slightly reduced in numbers. The inflammation was found to be remarkably uniform, indicating total colitis. Biopsy specimens taken after starting treatment with sulphasalazine showed fewer inflammatory cells in the lamina propria, though in none was inflammation completely abolished. In one patient (case 4) there was slight fibrous thickening of the epithelial basement membrane, though this was much less than that described in so-called collagenous colitis. ${ }^{12}$ The possibility that this degree of inflammation might be secondary to the diarrhoea was tested by comparing the biopsy specimens from these six patients with rectal and colonic biopsy specimens from other patients with chronic diarrhoea of comparable severity and duration. Some of these control patients had diarrhoea of known cause (ileal Crohn's disease, vipoma) while others had

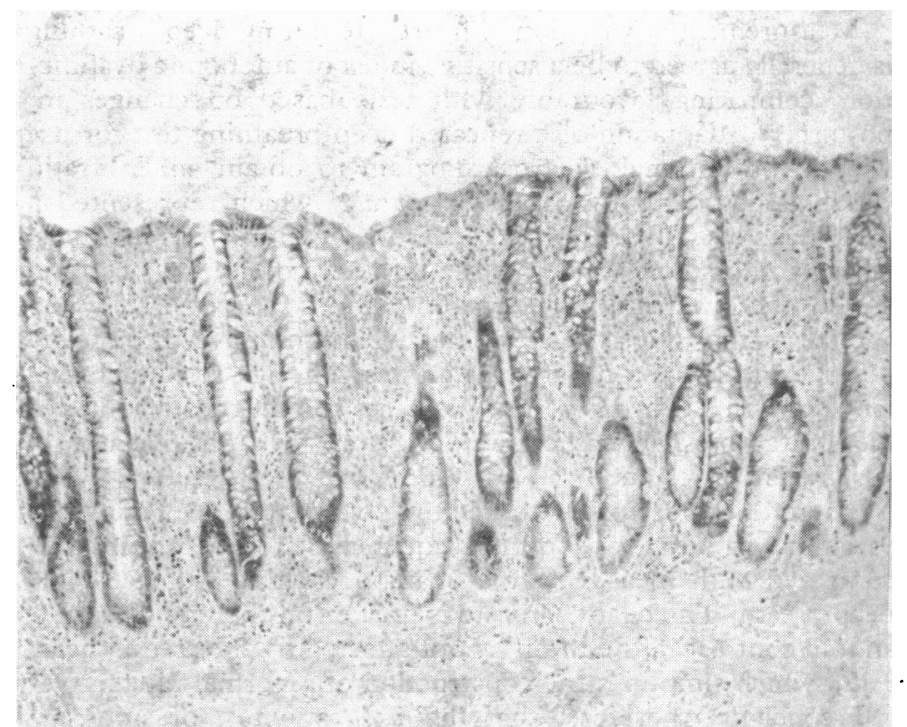

FIG 1-Rectal biopsy specimen from patient with microscopic colitis showing moderate diffuse chronic inflammation of the lamina propria and minimal goblet cell depletion. Haemotoxylin and eosin $\times 100$ (original magnification).

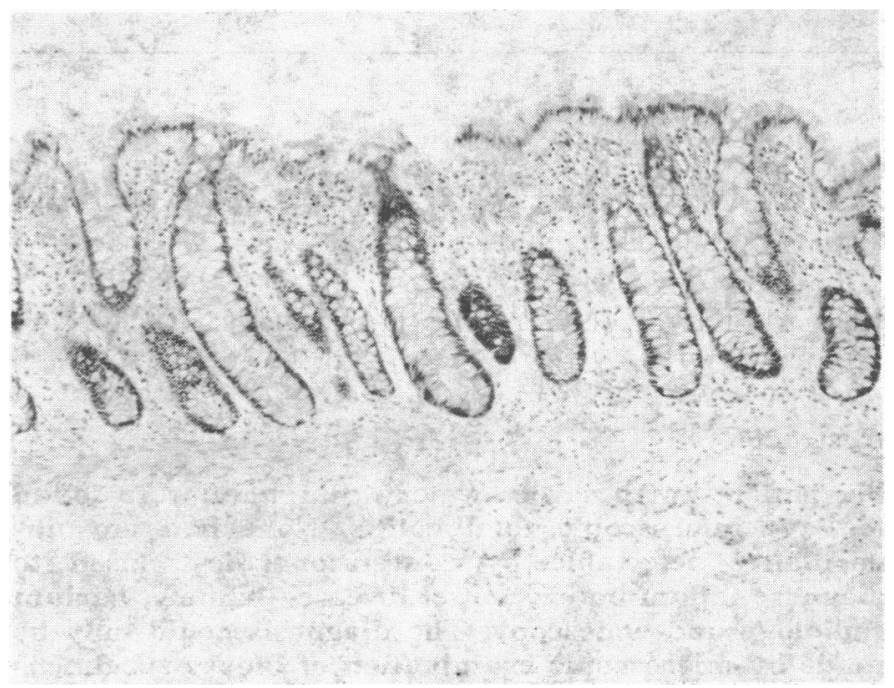

FIG 2-Rectal biopsy specimen without appreciable histological abnormality from a patient with chronic diarrhoea, still undiagnosed but not, by definition, microscopic colitis. Haemotoxylin and eosin $\times 100$ (original magnification).

TABLE I-Clinical details of six patients studied

\begin{tabular}{|c|c|c|c|c|c|c|c|}
\hline \multirow{2}{*}{ Case No } & \multirow{2}{*}{ Sex } & \multirow{2}{*}{ Age at presentation } & \multirow{2}{*}{ Duration of diarrhoea } & \multicolumn{2}{|c|}{ Volume of stools/day } & \multicolumn{2}{|c|}{ Frequency of stools/day and consistency } \\
\hline & & & & Before treatment & After treatment & Before treatment & After treatment \\
\hline $\begin{array}{l}1 \\
2 \\
3 \\
4^{*} \\
5 \\
6^{*}\end{array}$ & $\begin{array}{l}M \\
F \\
F \\
F \\
F \\
M\end{array}$ & $\begin{array}{l}41 \\
62 \\
56 \\
54 \\
61 \\
53\end{array}$ & $\begin{array}{l}1 \text { year } \\
25 \text { years } \\
1 \text { year } \\
20 \text { years } \\
4 \text { years } \\
3 \text { months }\end{array}$ & $\begin{array}{c}100-1000 \\
200-1200 \\
250-1700 \\
400-900 \\
1000-2100 \\
800-1100\end{array}$ & $\begin{array}{c}60-400 \\
130-500 \\
100-350 \\
150-350\end{array}$ & $\begin{array}{l}3 \text { watery } \\
12 \text { watery } \\
6 \text { watery } \\
6 \text { watery } \\
8 \text { watery } \\
5 \text { loose/watery }\end{array}$ & $\begin{array}{c}2 \text { soft } \\
3 \text { soft (occasionally loose) } \\
2 \text { formed (occasionally loose) } \\
2 \text { soft } \\
2 \text { firm (occasionally loose) } \\
4 \text { loose/watery }\end{array}$ \\
\hline
\end{tabular}

* Case 4 was unable to tolerate sulphasalazine and case 6 refused treatment. 
diarrhoea the cause of which was undiagnosed. The biopsy specimens from these control cases were all reported as normal when reviewed by one of us (DAL) and were identified as normal without hesitation when reviewed blind, mixed in with the microcolitic cases, by another pathologist (Dr A G Stansfeld) (fig 2).

fejunum and ileum-All six patients had at least one jejunal biopsy. In three patients these specimens were abnormal, the histological features showing subtotal villous atrophy in one, treated coeliac disease in one (mild partial villous atrophy and a slight excess of chronic inflammatory cells in the lamina propria), and mild non-specific inflammation in one. Further details of these three patients are given in the case histories. Three patients had ileal biopsies, which gave normal results.

\section{LABORATORY INVESTIGATIONS}

Table II gives the principal abnormalities found. Four had anaemia iron deficient in two, normochromic or normocytic in two; and in four the erythrocyte sedimentation rate was greater than $40 \mathrm{~mm}$ in the first hour. Four had low serum albumin concentrations and four had hypokalaemia during an attack of the diarrhoea. All the haematological and biochemical abnormalities returned to normal once remission had been induced.

Table III shows the investigations with essentially negative findings undertaken in the search for a cause of the diarrhoea. One patient (case 3) had been on a gluten-free diet for five years at the time of investigation. It is clear that standard tests of renal, liver, and absorptive function gave essentially normal results.

Findings of hormone screens were normal in all cases. There was no evidence of stool pathogens or small-bowel bacterial overgrowth Tests of pancreatic exocrine function (in five) and gastric acid secretion (in four) gave normal results. Jejunal perfusion studies in three patients showed normal absorption of sugar, amino-acids, water, and electrolytes.

In all patients purgative abuse was considered. To the best of our ability this was excluded by testing stools for phenolphthalein and urine for anthraquinones, and by careful search of the patient's personal belongings, bed, and bedside locker.

TABLE II-Principal abnormalities found in the six patients

\begin{tabular}{|c|c|c|c|c|c|c|}
\hline & 1 & 2 & 3 & 4 & 5 & 6 \\
\hline $\begin{array}{l}\text { Haemoglobin }(\mathrm{g} / \mathrm{dl}) \\
\text { Erythrocyte sedimentation rate }{ }^{\circ} \mathrm{mm} \text { in }\end{array}$ & $7 \cdot 3$ & $13 \cdot 8$ & $11 \cdot 0$ & $10 \cdot 2$ & $9 \cdot 7$ & $13 \cdot 8$ \\
\hline 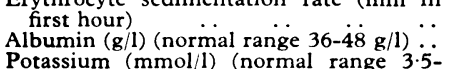 & $\begin{array}{l}43 \\
35\end{array}$ & $\begin{array}{l}77 \\
28\end{array}$ & $\begin{array}{l}47 \\
35\end{array}$ & $\begin{array}{l}23 \\
43\end{array}$ & $\begin{array}{l}43 \\
31\end{array}$ & $\begin{array}{r}5 \\
36\end{array}$ \\
\hline $5.0 \mathrm{mmol} / \mathrm{l})$ & $4 \cdot 4$ & $2 \cdot 3$ & $2 \cdot 1$ & $4 \cdot 0$ & $3 \cdot 3$ & $\cdot 3 \cdot 0$ \\
\hline
\end{tabular}

Conversion: $S I$ to traditional units-Potassium $=1 \mathrm{mmol} / 1 \approx 1 \mathrm{mEq} / \mathrm{l}$.

TABLE III-Results of investigations undertaken in search for cause of diarrhoea

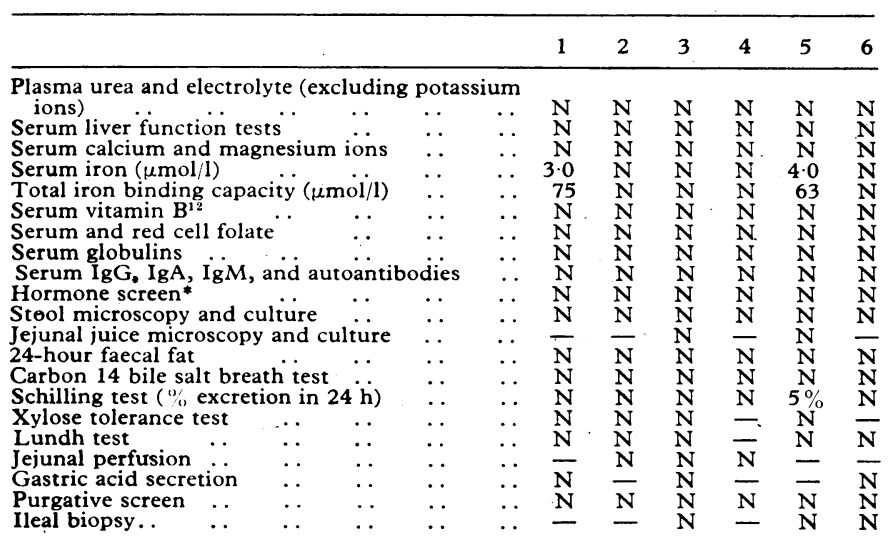

*Hormone screen-Gastrin, 5-hydroxyindole-acetic acid, thyroid function in all cases. Calcitonin, vasoactive intestinal polypeptide cases $1,2,4,5,6$. Glucagon, somatostatin, neurotensin cases 4, 5, 6 .

$\mathrm{N}=$ Normal.

No traditional units-Iron: $1 \mu \mathrm{mol} / 1 \approx 6 \mu \mathrm{g} / 100 \mathrm{ml}$. Total iron binding capacity: $1 \mu \mathrm{mol} / 1 \approx 6 \mu \mathrm{g} / 100 \mathrm{ml}$.

\section{CASE HISTORIES}

Three patients had abnormal findings on jejunal biopsy.

Case 2 presented with a long history of watery diarrhoea, unassociated with malabsorption (see table III). She was shown to have both microscopic colitis and subtotal villous atrophy. She ate a normal diet and was treated with sulphasalazine alone. which led to rapid clinical improvement and the return of the erythrocyte sedimentation rate and serum potassium concentrations to normal. Six months later repeat colonic and jejunal biopsies showed considerable improvement.

Case 3-This woman had presented initially with steatorrhoea, folate deficiency, and xylose malabsorption typical of coeliac disease. Jejunal biopsy confirmed subtotal villous atrophy. Clinical, biochemical, and histological remission of the coeliac disease was achieved within three months of starting gluten-free diet and has been maintained since. Her symptoms of colitis started some five years after the coeliac disease had been successfully treated: The diarrhoea was quite different, being profuse and watery without fat. She was treated with sulphasalazine $\mathbf{4} \mathrm{g}$ a day with considerable improvement. She remained on gluten-free diet throughout.

Case 5 had a three-year history of copious watery diarrhoea. Investigations showed both a microscopic colitis and a slightly abnormal jejunal biopsy specimen (minimal villous stunting and submucosal inflammation but normal epithelium). The changes were non-specific and did not suggest coeliac disease. There was no fat or folate malabsorption but B12 absorption was somewhat impaired (see table III). Treatment with steroids and sulphasalazine resulted in clinical, biochemical, and histological remission. Thereafter she remained well taking sulphasalazine alone.

\section{RESPONSE TO TREATMENT}

Five patients responded rapidly to treatment with anti-inflammatory agents used in inflammatory bowel disease. In two (cases 1 and 5) oral prednisolone and sulphasalazine were given initially and thereafter sulphasalazine alone (3-4 g/day) as maintenance. In two others (cases 2 and 3) sulphasalazine alone was used successfully ( $3 \mathrm{~g} /$ day). One further patient (case 4) was unable to tolerate sulphasalazine because of gastrointestinal side effects. She was given indomethacin $100 \mathrm{mg} /$ day with considerable improvement. The remaining patient (case 6) declined treatment and his condition is unchanged on follow-up.

\section{Discussion}

These six cases showed symptomatic colitis in the absence of endoscopic and $x$-ray changes. The diagnosis could only be made by biopsy and microscopy. The nature of this microscopic colitis has yet to be determined. The clinical picture does not suggest a close relation to ulcerative or Crohn's colitis: the severity of the diarrhoea would be quite atypical in conventional inflammatory bowel disease in the absence of gross disease and bleeding. Histologically, the uniform distribution of the colitis would be more akin to ulcerative than Crohn's colitis but there were no other histological features particularly suggestive of this or of infective or ischaemic colitis.

Microscopic colitis appears to be a clinical entity quite separate from "minimal change colitis" 3 in which, despite normal appearances on sigmoidoscopy and largely normal findings of barium enema, overt changes of Crohn's colitis proximal to the rectum were seen at colonoscopy. Extensive investigations in our six patients failed to reveal any other possible cause of diarrhoea, with the exception that three had abnormal jejunal biopsies. The importance of these jejunal lesions is unclear but they cannot reasonably account for the diarrhoea in the face of normal results of tests of absorptive function including jejunal perfusion. Indeed, this pattern of profuse watery diarrhoea would be rare even with severe malabsorption. Although occasional reports of coeliac disease and colitis in the same patient have appeared, ${ }^{45}$ the frequency suggests a chance association. There seems to be a commoner 
association between overt ulcerative colitis and less specific jejunal abnormalities ${ }^{6-8}$ whose severity reflects the clinical activity of the colitis.

Microscopic colitis is not generally recognised, though Read et $a l^{9}$ reported minor histological changes in the colon described as microscopic colitis in eight of 27 patients investigated for intractable diarrhoea. No conclusions, however, were drawn from this finding.

The possibility that surreptitious laxative ingestion caused the diarrhoea and microscopic colitis in our patients cannot be totally disproved. Nonetheless, we consider it unlikely as we failed to find laxatives in stool, urine, or personal belongings of the patients; melanosis coli was not found endoscopically and histologically; the histological changes in our cases differed from those described in the cathartic colon ${ }^{10}{ }^{11}$; and, most importantly, patients responded favourably to sulphasalazine.

We conclude that microscopic colitis is responsible for a proportion of cases of intractable diarrhoea of obscure origin and may respond to treatment with anti-inflammatory drugs. Rectal and colonic biopsies are mandatory in the investigation of such patients even though findings of colonic radiology and endoscopy are normal.

We thank Miss Helen Trussler for typing the manuscript.

\section{References}

${ }^{1}$ Lindstrom CG. "Collagenous colitis" with watery diarrhoea-a new entity? Pathologica Europa 1976;11:87-9.

${ }^{2}$ Teglbjaerg PS, Thaysen EH. Collagenous colitis: an ultrastructural study of a case. Gastroenterology 1982;82:561-3.

${ }^{3}$ Elliot PR, Williams CB, Lennard-Jones JE, et al. Colonoscopic diagnosis of minimal change colitis in patients with a normal sigmoidoscopy and normal air contrast barium enema. Lancet $1982 ; \mathrm{i}: 650-1$.

${ }^{4}$ Falchuk KR, Falchuk ZM. Selective IgA deficiency, ulcerative colitis and gluten sensitive enteropathy - a unique association. Gastroenterology $1975 ; 69: 503-6$.

${ }^{5}$ Kumar PJ, O'Donoghue DP, Gibson J, Stansfeld A, Dawson AM. The coexistence of inflammatory bowel lesions in coeliac disease. Postgrad Med f 1979;55:753-6.

${ }^{6}$ Salem SN, Truelove SL. Small intestinal and gastric abnormalities in ulcerative colitis. Br Med f 1965;i:827-31.

${ }^{7}$ Jankey N, Price LA. Small intestinal histochemical and histological changes in ulcerative colitis. Gut 1969;10:267-9.

${ }^{8}$ Binder V, Soltoft J, Gudmond-Hoyer E. Histological and histochemical changes in the jejunal mucosa in ulcerative colitis. Scand $\mathcal{F}$ Gastroenterol 1974;9:293-7.

${ }^{9}$ Read NW, Krejs GJ, Read MG, Santa Ana CA, Morawski SG, Fordtran JS. Chronic diarrhoea of unknown origin. Gastroenterology 1980;78: 264-71.

${ }^{10}$ Morson BC. Histopathology of cathartic colon. Gut 1971;12:867-8.

${ }^{11}$ Smith B. Pathology of cathartic colon. Proc R Soc Med 1972;65:288.

\title{
Rate of inactivation of cytomegalovirus in raw banked milk during storage at $-20^{\circ} \mathrm{C}$ and pasteurisation
}

\author{
HENRIK FRIIS， H KERZEL ANDERSEN
}

\begin{abstract}
Samples of milk from 23 mothers attending the department of obstetrics and gynaecology and 36 who donated milk to the department's milk bank were cultured for cytomegalovirus. Virus was isolated from samples from 12 of the milk donors but none of the mothers attending the department; follow-up studies during lactation in seven of these 12 women showed that five continued to excrete the virus. Samples were taken on three occasions from one woman who regularly excreted high titres of the virus. Storage at $-20^{\circ} \mathrm{C}$ for over three days reduced the titre by over $99 \%$; after pasteurisation at $63^{\circ} \mathrm{C}$ for eight minutes the milk did not contain any viable virus.

It is recommended that raw banked milk used for feeding preterm babies should be kept frozen for at least 72 hours before feeding.
\end{abstract}

\section{Introduction}

Recently it has been questioned whether human milk used to feed infants who cannot be breast-fed should be pasteurised or not because pasteurisation affects antimicrobial substances and nutritional properties of milk. ${ }^{12}$ Little attention, however, has been paid to the risk of transmitting cytomegalovirus infection by using raw banked milk. For this reason we studied the amounts of cytomegalovirus in human milk and the rate of

\footnotetext{
Institute of Medical Microbiology, University of Aarhus, DK-8000 Aarhus C, Denmark

HENRIK FRIIS, medical student

H KERZEL ANDERSEN, DMSC, reader in virology
}

inactivation of the virus during storage at $-20^{\circ} \mathrm{C}$ and during pasteurisation at $63^{\circ} \mathrm{C}$.

\section{Patients, methods, and results}

Milk samples were collected between days 2 and 12 from 23 mothers attending the university department of obstetrics and gynaecology at Aarhus Kommunehospital, and from 36 women who donated milk to the milk department's milk bank. Within four hours after collection $1 \mathrm{ml}$ of skimmed milk was inoculated into a $50 \mathrm{~cm}^{2}$ monolayer of human fibroblasts in glass bottles. After one hour of adsorption the cultures were overlaid with Eagle's modified medium and studied weekly for four weeks for a cytopathic effect typical for cytomegalovirus. Titres of cytomegalovirus were estimated by counting viral plaques in the cell layer after staining with methylene blue as described previously. ${ }^{3}$ Cytomegalovirus was not isolated from any samples from the 23 mothers attending the department but from 45 samples from 12 of the 36 milk donors. The earliest isolation was made in milk collected on day 14 and the latest in milk collected 58 weeks after delivery.

The initial cytomegalovirus titres were about 1000 plaque-forming units $(\mathrm{pfu}) / \mathrm{ml}$ in two women, 500 and $200 \mathrm{pfu} / \mathrm{ml}$ in two others, and about $10 \mathrm{pfu} / \mathrm{ml}$ in the rest. Follow-up studies performed during lactation in seven of the milk donors including three of the four women with initial titres of $200 \mathrm{pfu}$ or more $/ \mathrm{ml}$ showed that all except two continued to excrete cytomegalovirus, in titres of $10 \mathrm{pfu}$ or less $/ \mathrm{ml}$. One woman, however, regularly excreted between 1000 and 4600 $\mathrm{pfu} / \mathrm{ml}$ for 26 weeks of lactation; on three occasions samples obtained from her were divided and cultured after storage at $-20^{\circ} \mathrm{C}$ for up to 10 days. Storage for more than three days reduced the amount of cytomegalovirus in the milk by more than $99 \%$ (from $4300 \mathrm{pfu} / \mathrm{ml}$ to about $10 \mathrm{pfu} / \mathrm{ml}$ ) (figure). Pasteurisation at $63^{\circ} \mathrm{C}$, by heating aliquots of milk in a water bath for one, two, four, eight, and 16 minutes followed by quick cooling in an ice bath, also reduced the virus titre (from $3600 \mathrm{pfu} / \mathrm{ml}$ to $10 \mathrm{pfu} / \mathrm{ml}$ after one minute). After eight minutes of pasteurisation the milk did not contain any viable cytomegalovirus at all. 